Assiut Scientific Nursing Journal

http://asnj.journals.ekb.eg

http://www.arabimpactfactor.com

\title{
Effect of Nursing Education on Knowledge and Self Care for Patient's with Systemic Lupus Erythematosus
}

\author{
Mary Wageeh Sedrak ${ }^{1}$, Zienab Abd El-lateef Mohamad ${ }^{2}$, Elbadry Ibrahim Abo-EINoor ${ }^{3} \&$ Hanan Abd- \\ Elrazik Abd-Elall ${ }^{4}$ \\ 1. Bachelor of Science in Nursing- Technical Nursing Institute, Assiut University, Egypt. \\ 2. Professor of Medical- Surgical Nursing, Faculty of Nursing - Assiut University, Egypt. \\ 3. Professor of Internal Medicine, Faculty of Medicine - Assiut University, Egypt. \\ 4. Assistant Prof. of Medical - Surgical Nursing, Faculty of Nursing - Assiut University, Egypt.
}

\begin{abstract}
Patients with systemic lupus erythematosus are suffering from a lot of problems that can be overcomed by nursing education that focused on the improvement of patients' knowledge level, self-care. This study aimed to evaluate the effect of nursing education on knowledge level and self-care for patient's with systemic lupus erythematosus. Research design: This study was pre-post test research design was be utilized in this study. Sample: This study carried out on (200) patients with SLE, adult patients from both sex, their ages are ranged from (20-65) years old and are willing to participate in the study. Setting: The study was conducted in internal medical department (Rheumatology unit) at Assiut University Hospital. Tools: Two tools were used: patient assessment sheet, pre-post knowledge level and Self-Care questionnaire. Results: There were a statistical significant difference between total scores of knowledge level, self-care pre and post-test (after one month, after three month) after implementing nursing education $(\mathrm{P}=0.001)$. Conclusion: designed nursing education protocol were effective in improving knowledge level and self-care for patient with systemic lupus erythmatosus. Recommendation: Conducting additional studies on larger samples from a wider range of participants.
\end{abstract}

\section{Keywords: Nursing Education, Self-Care \& Systemic Lupus Erythmatosus.}

\section{Introduction}

Systemic lupus erythematosus (SLE) is an autoimmune disease that impacts many body systems, with a wide variety of signs and symptoms in each patient (Petri, et al., 2012). Systemic lupus erythematosus (SLE) is a chronic inflammatory disease that has protean manifestationsand follows a relapsing and remitting course. More than $90 \%$ of cases of SLE occur in women, frequently starting at child bearing age (Beckerman, 2015).

The overall incidence of SLE is estimated to be (1.8 to 7.6 ) per 100,000 persons. It occurs (6 to 10) times more frequently in women than in men and occurs more in African American populations than among Caucasians (Janice \& Kerry, 2014). In Egypt it was reported that; about (85) cases monthly are admitted to the rheumatology department in Cairo University Hospital with different signs and symptoms (Mostafa \& Abd-Elrehem, 2017). In Assiut University Hospital the total number of patients were admitted in (2018) was about (400) cases to medical and rheumatology department (Assiut University Hospital records, 2018).

Common symptoms include skin rashes, arthralgia, and fatigue; however, SLE can progress to serious organ involvement and end-stage renal disease. Patients with SLE experience periods of minimal or no disease activity (remission) and periods of increased activity (flares) (Bertsias \& et al., 2018).

The severe complications associated with SLE including, lupus nephrosis, lupus encepha-lopathy, grave pneumonitis and heart failure, have a damaging effect on the body, mind and members of the family of patients, especially women during the reproductive period (Xiangyingz, et al, 2016). Currently, no established standard treatment method is available, and the preferred treatment is the long -term administration of glucocorticoid or a combination of multiple immune inhibitors (Huang, et al., 2016)

Although no cure has been discovered for this autoimmune disease, many medications are available to help control flares, to maintain remission, and to manage symptoms. Pharmacists and other health care professionals can play a vital role in treatment by educating patients, monitoring their therapeutic regimens, and identifying preventable drug-associated adverse events. (Yousef, \& Foad, 2017) Patient education is an important but a complex issue. Nurses and physicians recognize the need for patient education. In the greatest number of cases the information that is important for the patient for the time being is outlined verbally or visualized, less focus is put on the secondary education aspects that are currently not in sight. 
The overall view of the situation is not less important because an educated patient is more engaged in solving problems, improving their health status, drug adherence , self-care, and future preventional measures. Educated, empowered patients and their relatives are active participants in maintaining health, forming an educated society.(Gunta Bēta, 2014)

By acquiring knowledge the patient self-care is improved through: stimulation of independent sign/symptom monitoring, medication management, enhancing problem-solving and decision-making skills for medical treatment management, and changing their physical activity, dietary, and/or smoking behavior (Jonkman, 2016).

\section{Significance of the study}

From the researcher experience with students of technical institute of nursing as clinical instructor during clinical round, it was observed that a continuous increasing of hospital systemic lupus erythematosus patients readmission rate with multiple effect on different body systems, Also understanding may help to improve medication compliance and selfcare and early detection of complications enables prompt intervention to prevent serious tissue damage or dysfunction (Lynda, 2014), So a significant understanding of their disease will help them to know how to be compliance with the treatment and maintain optimal self- care and follow precautions that will be helpful on decreasing the expected complications, So patients with SLE are in need for nursing education to improve their knowledge level about their disease to overcome the systemic complications.

\section{Aims of this study was to}

To evaluate the effect of nursing education on knowledge level and self-care for patient's with systemic lupus erythematosus.

\section{Hypothesis}

The knowledge level and self-care for the patients after the implementing nursing education will be improved than pre- implementing nursing education.

\section{Patients \& Methods \\ Technical design}

The technical design included research design, setting of the study, subjects, and tools for data collection.

\section{Research design}

Pre - post test research design was used in this study.

\section{Setting}

The study was conducted in Internal Medical Department (Rheumatology unit) at Assiut University Hospital

\section{Subject}

This study was carried out on (200) patients with SLE. The inclusion criteria is adult patients from both sex, diagnosed with SLE their ages are ranged from (20-65) years old admitted in internal medical department (rheumatology unit) at Assiut University Hospital.

Tools

Two tools were be used for data collection to achieve the purpose of this study:

Tool (I): Patient Assessment sheet:

It was developed by the researcher based on the current national and international literatures it includes three parts:

- Part (1): Demographic data patient sheet: To assess the demographic patient data and It includes (6) items are (Age, sex, marital status, occupation, level of education and residence).

- Part (2): Assessment of obstetric history: To assess the obstetric history and it includes (7) items are(age of menarche, days of menses, regularity of menses, numbers of pregnancy and abortions and preterm labor, type of family planning)

- Part (3): Assessment of medical patient history: To assess the medical patient history and it includes (7) items which are; (family history, past medical history, present medical history, onset of SLE disease, laboratory finding, physical examination and medical follow up).

Tool (II): Pre-post Knowledge Level and Self-Care Questionnaire sheet:

This tool was developed to assess general knowledge of SLE patients and the influence of educational exposure on knowledge level, self-care. This tool used pre-post after one month and after three months from the education. This tool includes two parts:

Part (1): General Level Knowledge Structured Questionnaire sheet (LKQ): It was developed by Shelbi Sullivan in (2016) aimed to assess general knowledge of SLE patients and to explore SLE knowledge and influence of educational exposure. It included (36) questions. The questions in the form of (yes or no) covered areas such as; definition, prevalence, causes, risk factors, signs and symptoms, SLE diagnosis, treatment, and complications of systemic lupus,....ect.

Part (2): SLE Self Care Practices Assessment sheet: by using the Appraisal of Self-Care Agency ScaleRevised (ASAS-R) is developed by (Sousa et al., 2010) and aimed to assess the personal self-care skills. It consists of (15) items, three factor version scale; factor one (having power for self-care, (6) items), factor two (developing power for self-care, (5) items), factor three (lacking power for self-care, (4) items). ASAS-R is a five-point likert scale.

Methods of data collection

This study was carried out in three phase: 


\section{Phase1:-Preparatory phase}

The researcher reviewed related literature of the current study, local \& international, using text books, articles, and scientific magazines. The proposed study setting was assessed for the numbers of patients in internal medical department (rheumatology unit) at Assuit University Hospital. This phase ended by a pilot study.

\section{Content validity and reliability}

The content validity of study tools were checked by 3 expert professors in field of nursing they reviewed the instruments for clarity, relevance, comprehensiveness, understanding, applicability and easiness for administrative minor modifications that required correction was carried out accordingly.

A pilot study

A pilot study carried out in Janury (2020) to test the feasibility and practicability of the study tools and conducted on (10\%) of the sample (20 patients) of sample. It had also provided an estimate of time needed to fill out the tools.

\section{Phase3:-Implementation phase}

1. Data were collected from internal medical department (rheumatology unit) at Assuit University Hospital for 6 months during the period from Janury 2020 to Augest 2020.

2. The study was carried out at morning and afternoon shifts for all available patients and by telephone.

3. At initial interview the researcher introduce herself to initiate line of communication, explain the nature and purpose of the study to the selected patients who are willing to participate in the study and fill out the questionnaire sheet Tool (1) to assess the patients demographic data, Obstetric, and medical patient history.

4. After assessment of the patients using the structured interviewing questionnaire sheet Tool (1) that filled through the researcher and assess general knowledge of SLE patients and the influence of educational exposure on knowledge level, self-care and drug adherence by using (LKQ), (MMAS-9) and (ASAS-R) sheets Tool (2) that filled through the researcher.

5. The nursing education booklet had been developed; the content meets the patients' needs, and their levels of understanding.

6. 6-All patients received the contents of nursing education by the researcher herself. The patients was divided into small group contain of (2-3 patient).

7. The nursing education was conducted through (2 sessions and 2 phone calls) and the duration of each session was around 20 to 30 minutes include 10 minutes for discussion and feedback.
8. Each of the following session usually started by a briefing about what had been discussed in the previous session, using simple Arabic Language.

9. Each session ended by a summary of what has been taught during the previous session and the objectives of new topics.

10. Feedback and reinforcement of nursing education was performed according to patients need to ensure their understanding.

11. Giving recognition to the interested patients was emphasized for motivation during the teaching. Each patient obtained a copy of the nursing education booklet that included the teaching content.

The first session: Was used to assess the patient using Tool (1) and Tool (2).

The (second) session: Was done used to implementing the theoretical part of nursing education for patients.

The (Third) session through phone call: After one month was done to assess the effectiveness of nursing education on improving patient's knowledge, self-care and drug adherence with SLE using Tool (2).

The (fourth) session through phone call: After three months from the education was done to assess the effectiveness of nursing education on improving patient's knowledge, self-care and drug adherence with SLE using Tool (2).

\section{Evaluation phase}

during this phase, an evaluation of the effectiveness of the nursing education on improving patient's knowledge, self-care and drug adherence with SLE was done through reassessing patient's knowledge, self-care and drug adherence pre and post implementing of designed protocol using Tool (2) after one month and after three months from the education.

\section{Administrative Design}

An official permission to carry out the study was obtained from the responsible hospital authorities of the internal medical department (rheumatology unit) at Assiut University Hospital and to achieve validity and reliability of tools, it was reviewed by experts nursing in the field of the study and necessary modifications were done.

\section{Ethical considerations}

1. Research proposal was approved from Ethical Committee in the faculty of nursing.

2. There is no risk for study subject during application of research.

3. The study was following common ethical principles in clinical research.

4. Oral consent was obtained from patients or guidance who are willing to participate in the 
study, after explaining the nature and purpose of the study.

5. Confidentiality and anonymity will be assured.

6. Study subject have the right to refuse to participate and or withdraw from the study without any rational any time.

7. Study subject privacy was considered during collection of data.

\section{Results}

Table (1): Frequency distribution of demographic characteristics for the study sample $(\mathrm{n}=\mathbf{2 0 0})$

\begin{tabular}{|l|c|c|}
\hline \multicolumn{1}{|c|}{ Demographic data } & $\mathbf{N}$ & $\%$ \\
\hline Sex & 200 & 100 \\
Femal & 0 & 0 \\
Male & & \\
\hline Age group & 81 & 40.5 \\
\hline 20-<35yrs & 115 & 57.5 \\
\hline 35-<45yrs & 4 & 2.0 \\
\hline 45-<55yrs & & 56.0 \\
\hline Marital status & 112 & 24.5 \\
\hline Married & 49 & 5.5 \\
\hline Single & 11 & 14.0 \\
\hline Widow & 28 & \\
\hline Divorce & & 1.5 \\
\hline Professional level & 3 & 9.0 \\
\hline Student & 18 & 89.5 \\
\hline Work & 179 & 2.0 \\
\hline Not work & & 98.0 \\
\hline Level of education & 4 & 74.5 \\
\hline Non-educated & 196 & 25.5 \\
\hline Educated & & \\
\hline Address & 149 & \\
\hline Rural & 51 & \\
\hline Urban & & \\
\hline
\end{tabular}

Table (2): Frequency distribution of medical history $(n=200)$

\begin{tabular}{|l|c|c|}
\hline \multicolumn{1}{|c|}{ Items } & N & \% \\
\hline Family history & & 99.5 \\
\hline No & 199 & .5 \\
\hline Yes & 1 & 97.5 \\
\hline Chronic disease & 195 & 2.5 \\
\hline No & 5 & .5 \\
\hline Yes & & 2.0 \\
\hline If yes & 1 & 1.5 \\
\hline Heart & 4 & .5 \\
\hline Joint disease & & .5 \\
\hline Duration & 3 & \\
\hline 1-5yrs & 1 & \\
\hline 5-10yrs & 1 & \\
\hline More than 10 yrs & & \\
\hline Current complain & 4 & \\
\hline Skin disease & & \\
\hline
\end{tabular}




\begin{tabular}{|l|c|c|}
\hline \multicolumn{1}{|c|}{ Items } & N & \% \\
\hline High temp. & 2 & 1.0 \\
\hline Joint pain & 4 & 2.0 \\
\hline Skin and joint pain & 108 & 54.0 \\
\hline High temp & 31 & 15.5 \\
\hline Skin disease and joint pain & 9 & 4.5 \\
\hline High temp and joint pain & 12 & 6.0 \\
\hline When start & 59 & \\
\hline Less than one year & 133 & 29.5 \\
\hline 1-5yrs & 7 & 66.5 \\
\hline 5-10yrs & & 3.5 \\
\hline Times of follow up & 78 & \\
\hline Regular & 121 & 39.0 \\
\hline When necessary & & 60.5 \\
\hline
\end{tabular}

Table (3): Comparison between patient knowledge and follow up $(n=200)$.

\begin{tabular}{|c|c|c|c|c|c|c|c|}
\hline \multirow{3}{*}{$\begin{array}{l}\text { Total knowledge } \\
\text { 0-36 degree }\end{array}$} & \multirow{2}{*}{\multicolumn{2}{|c|}{ Pre-test }} & \multicolumn{4}{|c|}{ Follow up } & \multirow{3}{*}{ P. value } \\
\hline & & & \multicolumn{2}{|c|}{ One month } & \multicolumn{2}{|c|}{ After 3 month } & \\
\hline & $\mathbf{N}$ & $\%$ & $\mathbf{N}$ & $\%$ & $\mathbf{N}$ & $\%$ & \\
\hline Good knowledge $>75 \%$ & $\mathbf{0}$ & 0.0 & 151 & 75.5 & 199 & 99.5 & \multirow{4}{*}{$.001 * *$} \\
\hline Average or fair 50-75\% & 4 & 2.0 & 49 & 24.5 & $\mathbf{0}$ & .0 & \\
\hline Poor knowledge $<50 \%$ & 196 & 98.0 & $\mathbf{0}$ & $\mathbf{0}$ & 1 & 0.5 & \\
\hline Means \pm SD & \multicolumn{2}{|c|}{$10.17 \pm 5.35$} & & 5.11 & \multicolumn{2}{|c|}{$35.78 \pm 2.55$} & \\
\hline
\end{tabular}

(Chi-saqure test and one way anova test with significant difference $p=0.001$ )

Table (4): Comparison between patient lacking power of self care and follow up ( $n=200)$.

\begin{tabular}{|c|c|c|c|c|c|c|c|}
\hline \multirow{3}{*}{ Self-care : Total score $15-75$} & \multirow{2}{*}{\multicolumn{2}{|c|}{ pre-test }} & \multicolumn{4}{|c|}{ Follow up } & \multirow{3}{*}{ p.value } \\
\hline & & & \multicolumn{2}{|c|}{ One month } & \multicolumn{2}{|c|}{ After 3 month } & \\
\hline & $\mathbf{N}$ & $\%$ & $\mathbf{N}$ & $\%$ & $\mathbf{N}$ & $\%$ & \\
\hline Low level of self-care & 85 & 42.5 & 64 & 32.0 & 1 & 0.5 & \multirow{3}{*}{$.001 * *$} \\
\hline Middle level of self-care & 113 & 56.5 & 112 & 56.0 & 170 & 85.0 & \\
\hline High level of self-care & 2 & 1.0 & 24 & 12.0 & 29 & 14.5 & \\
\hline Mean \pm SD & \multicolumn{2}{|c|}{$46.52 \pm 7.83$} & \multicolumn{2}{|c|}{$50.17 \pm 9.05$} & \multicolumn{2}{|c|}{$56.12 \pm 2.29$} & \\
\hline
\end{tabular}

(Chi-saqure test and one way anova test with significant difference $p=0.001$ )

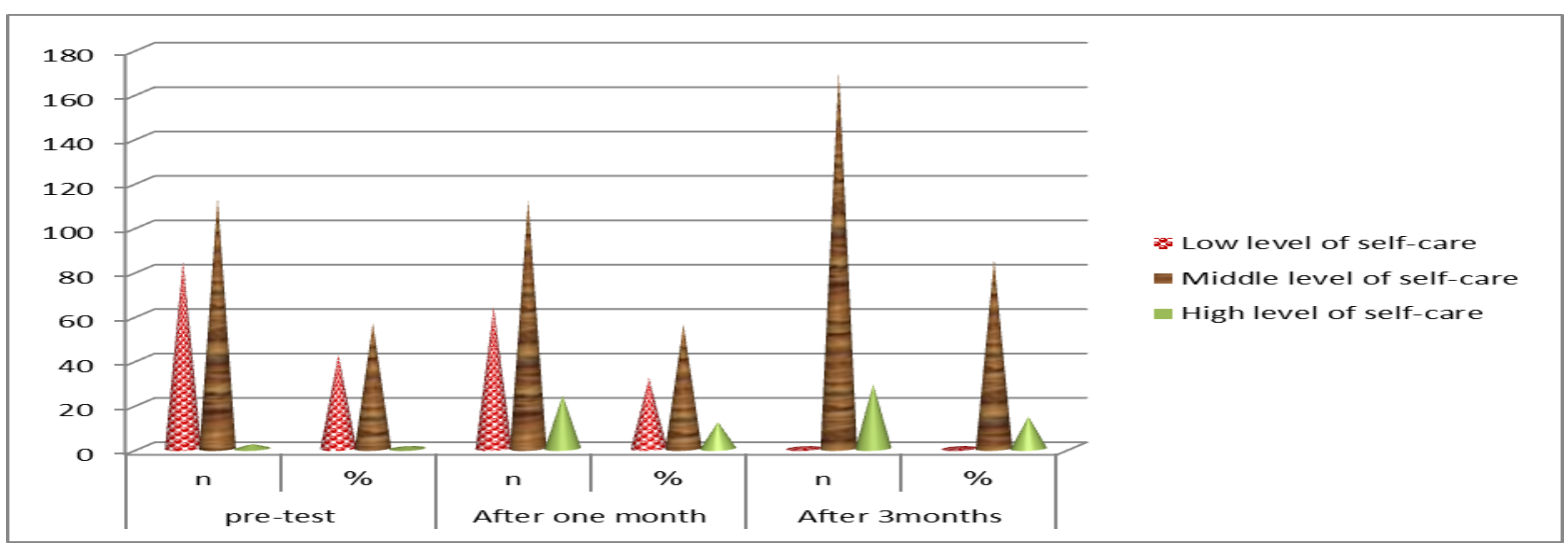

Figure (1): Comparison between self- care pre- after nursing education. 


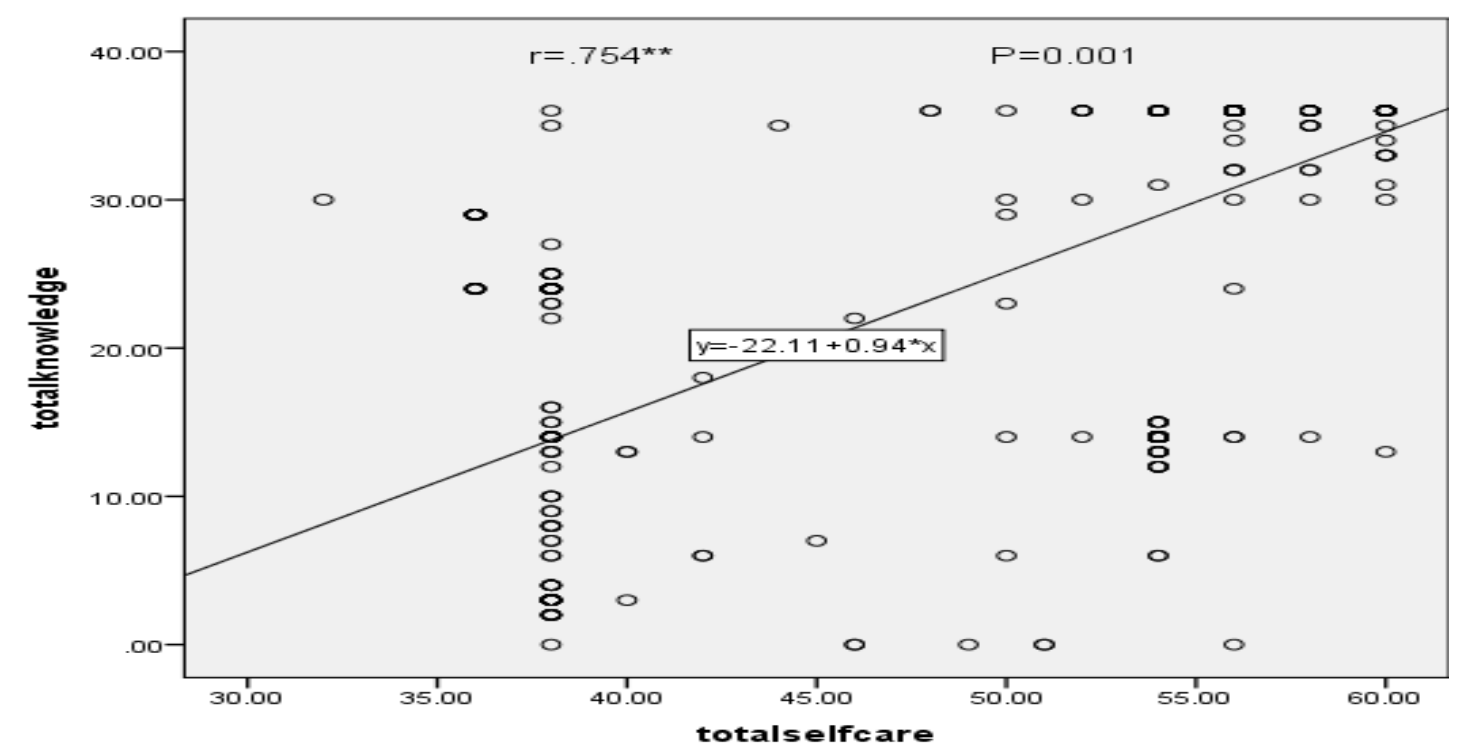

Figure (2): Correlation of the studied sample total knowledge and self care

The results in the present study will be presented into the following parts

Part 1. Demographic data of the studied sample:

This part is concerned with demographic characteristics of the studied sample among SLE patients including (6) items are (age, sex, marital status, occupation, level of education and residence).

Table (1).

Part 2. Assessment of Medical Patient History: To assess the medical patient history and it includes (7) items which are; (family history, past medical history, present medical history, onset of SLE disease). Table (2)

Part 3. General Level Knowledge Structured Questionnaire sheet (LKQ): To assess general knowledge of SLE patients and to explore SLE knowledge and influence of educational exposure. It included (36) questions. The questions in the form of (yes or no) covered areas such as; definition, prevalence, causes, risk factors, signs and symptoms, SLE diagnosis, treatment, and complications of systemic lupus, ....ect. Table (3)

Part (4). SLE Self Care Practices Assessment sheet: To assess the personal self-care skills. It consists of (15) items, three factor version scale; factor one (having power for self-care, (6) items), factor two (developing power for self-care, (5) items), factor three (lacking power for self-care, (4) items). ASAS-R is a five-point likert scale. Table (4).

Table (1): Reveals that all studied sample was femal, The highest percentage of the studied sample (56, $0 \%$ ) were married, The majority of them their age ranged from (35-45) years old (57,5\%) and almost of them not working $(89,5 \%)$, The majority of them were educated $(34,0 \%)$, and living in rural $(74,5 \%)$.
Table (2): Illustrate that their age of menstruation by mean $13,83 \pm 1,05$ and the majority of them $(66,5)$ had irregular menstruation and the mean of number of days of menses was $2.93 \pm 1.017$ and number of pregnancy $2.71 \pm 2.22$ and number of abortion was $.49 \pm .82$, The majority of them don't use contraceptive $(70.5 \%)$ and the lowest percentage $(29,5 \%)$ use contraceptive loop $(17,0 \%)$

Table (3): Reveals that the majority of them don't have family history $(99,5 \%)$ and didn't suffer from chronic disease $(97,5 \%)$ and the highest percentage of chronic disease was joint disease $(2,0 \%)$, The highest duration of chronic disease was $(1,5 \%)$, The majority of them had the current complain was skin and joint pain and other $(54,0 \%)$, The highest percentage of them start between (1-5) years old by $(66,5 \%)$, The majority of them their times of follow up was $(60,5 \%)$ Table (4) : Show that there was ahighly statistical significant difference in SLE patient knowledge in the pre- post test (after one month and three month) for the study sample with a $\mathrm{p}$. value $=0.001$.

Table (5): Show that there was ahighly statistical significant difference in SLE patient power of self care in the pre- post test (after one month and three month) for the study sample with a p. value $=0.001$.

Figure (1): Illustrate that there was ahighly statistical significant difference in SLE patient power of self care in the pre- post test (after one month and three month) for the study sample with a $\mathrm{p}$. value $=0.001$.

Figure (2): This figure illustrate apositive correlation between total knowledge and self care. 


\section{Discussion}

Systemic lupus erythematosus (SLE) is an episodic, multisystem, autoimmune disease characterized by widespread inflammation of blood vessels and connective tissue. There is no cure for lupus, but medical interventions and lifestyle changes can help control it. The seriousness of SLE can range from mild to life-threatening. Patients with lupus who get proper medical care, preventive care, and education can significantly improve function and quality of life Brown, et al., (2012). The aim of this study is to evaluate the effect of nursing education on knowledge level and self-care for patient's with systemic lupus erythematosus.

As regards gender of the patients in the present study, it was showed that all of them were females. This in the same line with Tsokos, (2013)who stated that SLE affecting women nine times than men and agreeable with Abd El latifa E., et al., (2018) that thay told most of the cases of SLE occur in women, frequently starting at childbearing age. This explained by Sanz, (2010)who mentioned that; the biggest difference in the occurrence of lupus between men and women may be because women experience highest exposure to estrogen hormone, it is also possible that the male hormone, androgen, may have a protective function in lupus.

Also according to the age group of the patients in the current study, the present study revealed that; they were around (20 to 45 years). This is agreement with Sestak, et al., (2011) who stated that; the most common age for SLE is between 15-45 years which is called the bearing age which means that in this period hormones influencing vulnerability to this disease.

According to marital status majority of them are married. These findings were consistent with O'Riordan, et al., (2017) who found that all participants were female and the majority were married. According to professional level of the patients in the current study the majority of the patient not working and this agreement with Mostafa \& Abd-Elrehem (2017) they reported that the majority of the patient not working. And according to education level of the patients in the current study the most patient were educated, and more than half of them are rural and this agreement with Elsayed, and Mesbah, (2018), that stated that the majority of the patient were rural.

As regards to the obestatric history of the current study sample had disturbance and irregularity in menstruation and this agree with Jose Ordi-Ros, et al., (2019) that stated Patients with SLE may have menstrual disturbances or even amenorrhea secondary to very active disease. As regards to the number of pregnancies was $2.71 \pm 2.22 \mathrm{SD}$ and number of abortion was $0.49 \pm 0.82 \mathrm{SD}$ in the current study and this agree with Sylvia, et al., (2017) Who stated that the mean number of pregnancies per patient was $2.4 \pm 1.4 \quad \mathrm{SD} \quad$ (including miscarriages), and miscarriage rate was $14 \%$ with a mean of $0.33 \pm 0.7$ SD per woman during the studied reproductive period.

As regards to the onset of disease. The present study findings showed that around majority of patients with SLE had ranged from less than one year to less than five year. This result congruent with Macejová, et al., (2013). Who stated that the onset of disease among participants was from 1-5 years.

The present study revealed that, there was a highly statistical significant difference in SLE patient knowledge in the pre- post- test (after one month and three month) for the study sample, this study finding was supported by Sahebalzamani et al., (2017) mentioned that, the continuous education significantly improved patients' knowledge level and awareness of their disease. This study finding was supported by Mohamed \& Kamel, (2018) which founded that the health education based intervention had a significant effect on the improvement of SLE patients' knowledge However, after application of the designed nursing education the patients had a highly significant improvement. This result supports the study hypothesis which suggested that the knowledge level and self-care for the studied group patients after the implementing nursing education improved than preeducation.

According to self care of the patients in the current study was improved after nursing education and this result is agreeable to another study by Hui et al., (2018)Previous research revealed that the process of learning or teaching and guidance from others enable the development and promotion of self-care. This finding in the same line with Mohamed and Kamel (2018) who reported that the health education based intervention had a significant effect on the improvement of SLE patients' self-care practices.

Finally, from the researcher's opoinion this study result indicated that the knowledge level and self-care for the studied group patients improved after nursing education. The post test indicated highly significant differences in the scores between pre and post-test indicating the effect of nursing education on improvement of knowledge level and self-care in SLE patients.

\section{Conclusion}

Based on the result of the present study, it can concluded that there was a highly statistical significance difference between total scores of the knowledge level and self care level pre and post-test( after one month, two month and after three months) 
$\mathrm{P}=0.001$.After nursing education for systemic lupus erythematosus patients

\section{Recommendations}

In the light of the findings of the current study the following recommendations were suggested:-

1- The nursing staff should provide patients continuous health education at Rheumatology department about the disease and self care by using booklet.

2- Replicate of the study in different areas to generate the study result.

3- Future research is proposed to explore the effect of self care protocol on outcomes of patients with SLE.

\section{References}

- Abd- El latifa E., Hassana Z., \& Gomaa A., (2018): Effect of systemic lupus on patient's selfesteem and quality oflife, Egyptian Nursing Journal, Vol.(15), No.(3), P.p:156-161.

- Assiut University Hospital Records, (2018).

- Beckerman N., (2015): Living with lupus: a qualitative report. Soc Work HealthCare, Vol. (50), No.(3), P.p:330-343.

- Bertsias G., Pamfil C., Fanouriakis A., \& Boumpas D., (2013): Diagnostic criteria for systemic lupus erythematosus: has the time come, Nat Rev Rheumatol ,Vol(9), No.(6), P.p:687-94.

- Brown, R., Shaftman, S., Tilley, B., Anthony, K., Kral, M., Maxson, B., \& Nietert, P., (2012): The health education for lupus patients study, A randomized controlled cognitive behavioral intervention targeting psychosocial adjustment and quality of life in adolescent females with systemic lupus erythematosus. American Journal of Medical Science, Vol.(344), No.(4): P.p:274-282.

- Elsayed D., \& Mesbah S., (2018): Effect of Health Education based Intervention on Self-care among Systemic Lupus Erythematosus Clients." American Journal of Nursing Research, Vol. (6), No. (3), P.p:105-112.

- Gunta Bēta, C., (2014): Patient Education Relevance in Nursing Education and Practice, American Journal of Educational Research, Vol. (2), No. (7), P.p:441-446.

- Huang X., Magder L., \& Petri M., (2016): Predictors of incident seizure in systemic lupus erythematosus. J Rheumatol, Vol. (43), No.(3), P.p:565-575.

- Hui Y., Xie X., Yuqing S., Anliu N., Hong C., (2018): self-care agency in systemic lupus erythematosus and its associated factors: a crosssectional study, Dove press journal,Patient Preference and Adherence 2018, Vol.(12), No.(3), P.p: $607-613$
- Janice L., \& Kerry H., (2014): Assessment and management of patients with rheumatic disorders, Brunner\&Suddarth'sTextbook of medical surgical nursing, chapter (39), (13) edition, Wolters Kluwer_Lippincott Williams Wilkins, China, P.p:1069-1072.

- Jonkman M., (2016): Autoimmune bullous diseases (Text and Review). 1st edition, Springer International Publishing, Swizerland, P: 152.

- Jose O., Cristina S., \& Josefina C., (2019): Lupus Pregnancy: Risk Factors and Management, Lupus New Advances and Challenges, Sophia Lionaki, IntechOpen, Vol. (6), No. (3), P.p:27-41

- Lynda, J.S. (2014): Infectious and immunodeficient disorders, Nursing Care Plans Transitional Patient\&Family Centered Care, 6 Th editions, J.B. Lippincott company, USA, P.p:599606.

- Macejová Z., Záriková M.,\& Oetterová M., (2013): SYSTEMIC LUPUS ERYTHEMATOSUS - DISEASE IMPACT ON PATIENTS, Slovakia, Cent Eur J Public Health, Vol.(21), No.(3): P.p:171173

- Mohamed D., and Kamel S., (2018): Effect of Health Education based Intervention on Self-care among Systemic Lupus Erythematosus Clients." American Journal of Nursing Research, Vol.(6), No.(3), P.p:105-112.

- Mostafa, H., \& Abd-Elrehem T., (2017): SelfManagement Guidelines, Effect on Awareness of Patients with Systemic Lupus Erythmatosus, Egypt, IOSR Journal of Nursing and Health Science; Vol.(6), No(6), P.p:15-23.

- O'Riordan R., Doran M., \&Connolly D., (2017): Fatigue and Activity Management Education for Individuals with Systemic Lupus Erythematosus. Hindawi. Occupational Therapy International, Vol.(2017), No.(30), P.p:1-11

- Petri M., Orbai A.,\& Alarcón G., (2012): Derivation and validation of the Systemic Lupus International Collaborating Clinics classification criteria for systemic lupus erythematosus, Arthritis Rheum., Vol.(64), No.(12),P.p:2677-2686.

- Sahebalzamani M., Farahani H., Jamarani T., Faezi T., Moradi K., \& Paragomi P., (2017): Effects of a Continuous Care Model on Patients' Knowledge and Health-Related Quality of Life in Systemic Lupus Erythematosus. Rehabil Nurs., Vol.(42), No.(6), P.p: 9-18

- Sanz Y., (2010): Experimental reproduction of skin lesions in lupus erythematosus by UVA and UVB radiation.J Am Acad Dermatol,Vol.(22), No.(2 Pt 1), P.p:181-187. 
- Sestak A., Fürnrohr B., Harley J., Merrill J., \& Namjou B., (2011):The genetics of systemic lupus erythematosus and implications for targeted therapy.Ann Rheum Dis., Vol.(70), No.(1), P.p:3743

- Shelbie S., (2016): Development of a systemic lupus erythemasosus knowledge questionnaire (The relationship among disease proximity and educational exposure and knowledge development), thesis of Master of Science in psychology, University of Wisconsin-Milwankee. https://www.researchgate.net/publication/30964434 0

- Sohng T., Murdaca G., Colombo B., \& Puppo F., (2011): Emerging biological drugs: a new therapeutic approach for Systemic Lupus Erythematosus. An update upon efficacy and adverse events.Autoimmun Rev., Vol.(11), No.(1), P.p:56-60

- Sousa V., Zauszniewski J., Bergquist-Beringer S., Musil C., Neese J., \& Jaber A., (2010): Reliability validity and factor structure of the Appraisal of Self-Care Agency Scale-Revised (ASAS-R), Journal of Evaluation in Clinical Practice, Vol.(16), No.(6), P.p:1031-1040.

- Steven K., (2012): Sample size, Sampling, Third edition, Wiley series in probability and statistics, Canada, P.p:59-60.

- Sylvia J., Carolien N., Birgit S., , Jacob M., Ronald W., Irene E., Alexandre E., Marjon A., Johanna I., \& Ruth D., (2017): "Maternal and Perinatal Outcome in Women with Systemic Lupus Erythematosus: A Retrospective Bicenter Cohort Study", Journal of Immunology Research, Vol.(2017), No.(4), P.p: 9.

- Tsokos G., (2013): Systemic lupus erythematosus.N Engl J Med. Dec 2011, Vol.(365), No.(22), P.p:2110-2121

- Xiangyingz., Yali T., Junbao L., \& Xingli Z., (2016): Effect of targeted nursing applied to SLE patients, Exp Ther Med., Vol.(11), No.(6), P.p:2209-2212.

- Yousef T., \& Foad A., (2017): Diagnosis and Management of Systematic Lupus Erythematosus (SLE), The Egyptian Journal of Hospital Medicine, Vol.(67), No.(2), P.p:672-678. 